\title{
Changes in muscular strength based on full cervical flexion
}

\author{
Janis Vetra ${ }^{1}$, Vladimir Sklarevich ${ }^{1}$, Gregory Anoufriev ${ }^{2}$, Imants Kalnins ${ }^{1}$, Janis Vetra Jr. ${ }^{1}$, \\ Silvija Umbrasko ${ }^{1}$, Vladislavs Kotovs ${ }^{3}$, and Larisa Beilina ${ }^{4}$ \\ ${ }^{1}$ Rīga Stradinsš University, Latvia \\ ${ }^{2}$ College of Health Sciences, Appalachian State University, USA \\ ${ }^{3}$ Clinic "Gimenes veseliba", Latvia \\ ${ }^{4}$ Chalmers University of Technology and Gothenburg University, Sweden
}

\begin{abstract}
We present our study of influence full cervical flexion position on the changes in muscle strength of the upper extremities. This position is typical for a person working on mobile phone or iPad. The purpose of the study was determination of the connection between change of the head flexed position and changes in upper extremity muscles strength. The present study involved 80 healthy volunteers and was performed at the Department of Morphology in Riga Stradins University, Riga, Latvia. For measurements we have used the MicroFET2 Hand Held Digital Muscle Tester to determine the strength of the muscles of the hand and arm (M. abductor pollicis longus, $M$. biceps brachii, $M$. triceps brachii, $M$. deltoideus). The results of measurements were then used to analyze the difference in the strength of the muscles innervated by the spinal cord cervical region (C5-C8 nerves) for the same person sitting in the vertical position and sitting with the head flexed maximally. The results of our study support the hypothesis that the changes in the strength of measured muscles are related to the mechanical distension of the spinal cord, which leads to changes in spinal cord's blood supply. The kyphotic position of the cervical spine during head flexion shows that in the spinal cord segments C5 and C7 are formed mechanical distension. Using our statistical study, we can conclude that there is strong relationship in the strength change in some of the observed muscles between vertical position and full flexion of head
\end{abstract}

Key words: muscle strength of the upper extremities, spinal cord, cervical region flexion, work environment, text neck.

\section{Introduction}

The concept "text neck" is used to describe a set of health problems resulting from long-term holding head in a forward bending position, acting with smartphones, tablets or other type of electronic communication devices.

The most typical manifestations are pain and stiffness in the neck or shoulder, and a tingling sensation in the hands. More severe cases can result in heart, brain blood supply and blood pressure problems.

It is widely studied and frequently reminded - bending the head forward causes an additional load to vertebral joints and intervertebral disks. Overload causes degenerative changes in bone and cartilage, and over a long period it results in narrowing of intervertebral opening or disc hernia, which can lead to spinal nerve or nerve root irritation with following pain, muscle tension, tingling sensation in hands and other sensory disorders [1-6]. 


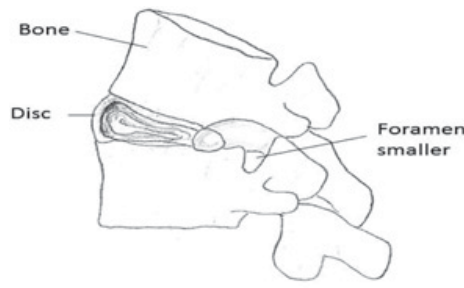

(a) Extension

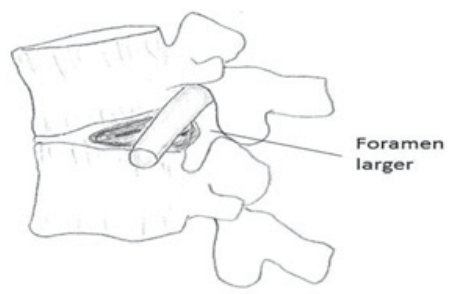

(b) Flexion

Fig. 1. Intervertebral foramina's widening by neck flexion.

However, it is not possible to explain all "text neck" pathologic changes with a deformed spine and spinal nerve irritation. Physical Medicine and Rehabilitation physicians, neurologists, orthopedists in their clinical practice have observed and described a phenomenon - patients' hand muscle strength changes by bending patients' head forward from upright (vertical) position to chin-to-chest position. That is, the changes in limb muscle strength are caused by changing the cervical spine curvature from lordosis to kyphosis position.

The changes in limb muscle strength from head bending in not due to spinal nerve pressing between vertebrae, because the intervertebral openings are expanding when changing the backbone position from lordosis to kyphosis and thus reducing the possibility of mechanical effect on the spinal nerves (Fig. 1).

However, there are changes in the limb muscle strength and in accordance with empirical clinical observations - more expressed in patients with chronic back pains.

Limb muscle strength changes by changing the curves of the spine from lordosis to kyphosis position, is present in all human beings - both practically healthy and patients with musculoskeletal pathology, but to varying degree. It is considerable to be a universal response to the changes of spine functional position.

The reduction of muscle strength occurs instantly, as soon as the head is bent forward (cervical spine lordosis position to kyphosis) and immediately is lost when restoring the normal (vertical) lordosis position of cervical spine.

This fact cannot be explained by changes of the vertebral column geometry. The available scientific literature sources mention this phenomenon, see for example [7], but the information they provide is based on patient observation only. No explanations are given with regards to its possible cause. Therefore, we have interest to clarify the nature of this clinical phenomenon and establish some parameters, in order to better understand it.

Our earlier study we found statistically significant differences between the muscle strength of the spine in vertical position and the head 30 degrees flexion position for 3 of 4 pair of tested muscles (M. biceps brachii, M. triceps brachii, M. deltoideus) [8]. This position is typical for a person working in front of a computer.

The goal of this research is to study changes in the specific muscles strength of the arm and hand (M. abductor pollicis longus, M. biceps brachii, M. triceps brachii, M. deltoideus) when the cervical spine is in vertical position and while the head is maximally flexed, to compare present data with earlier study ( $30^{\circ}$ head flexion), as well as to find out what level of spinal cord could be attributed as a possible cause for this phenomenon.

\section{Methods}

Our study has been approved by the Ethics Committee of Riga Stradinš University (RSU), resolution number 55/29.01.2015, Chairperson Professor Olafs Bruvers. The date of approval is 29.01.2015. 
Table 1. Volunteer demographics.

\begin{tabular}{|l|c|c|c|c|c|c|}
\hline & \multicolumn{2}{|c|}{ Female } & \multicolumn{2}{c|}{ Male } & \multicolumn{2}{c|}{ Total } \\
\hline Age & Flexion $30^{\circ}$ & Full flexion & Flexion $30^{\circ}$ & Full flexion & Flexion $30^{\circ}$ & Full flexion \\
\hline 19 & 5 & 7 & 5 & 4 & 10 & 11 \\
\hline 20 & 28 & 18 & 11 & 8 & 39 & 26 \\
\hline 21 & 25 & 12 & 11 & 6 & 36 & 18 \\
\hline 22 & 3 & 4 & 2 & & 5 & 4 \\
\hline 23 & & 3 & 1 & 4 & 1 & 7 \\
\hline 24 & 1 & 1 & & 4 & 1 & 5 \\
\hline 25 & 2 & 1 & & & 2 & 1 \\
\hline 26 & 1 & 1 & 1 & 2 & 2 & 3 \\
\hline 27 & 1 & 1 & 1 & 2 & 2 & 3 \\
\hline 28 & 1 & & & 1 & 1 & 1 \\
\hline 29 & & 1 & & & & 1 \\
\hline 30 & 1 & & & & 1 & \\
\hline Total & $\mathbf{6 8}$ & 49 & $\mathbf{3 2}$ & $\mathbf{3 1}$ & $\mathbf{1 0 0}$ & $\mathbf{8 0}$ \\
\hline
\end{tabular}

The present study (full head flexion) involved 80 volunteers in the age from 19 to 30 years old and results was compared with previous group ( $30^{\circ}$ head flexion) of 100 volunteers, with no health issues, see Table 1. for volunteer demographics. Volunteers had given their informed consent for participation in the research study. All measurements were performed on persons in sitting position, using a standardized chair DXR ACER. The functional elements of the chair were adjusted in such a way so that the individuals' elbow joints should be at a $90^{\circ}$ - arms should be supported on the armchair and lumbar region of spine column had individually adaptive support to maintain lumbar region of tested person in fixed lordosis position.

The MicroFET2 Hand Held Digital Muscle Tester was used according to the manufacturer recommendations. During testing strength was measured in the muscles of the hand and arm (M. abductor pollicis longus, M. deltoideus, M. biceps brachii, M. triceps brachii) [see Fig. 2 for experimental setup]. Each muscle test was performed at least twice (with one repetition). The time that was spent for each test of muscle measurement was the same. This time was determined automatically by the MicroFET2 Hand Held Digital Muscle Tester manual test system. Testing was completed when the display read "valid". All measured results of strength of the muscles were given in Newtons. The trials were performed on the same subjects to determine the strength of the same muscles in two different body positions. Each measurement of muscle strength was recorded when the cervical spine was in vertical position, during the flexion of the head at $30^{\circ}$, and during flexion greater than $30^{\circ}-$ full flexion.

The main tendency is described by the average value and distribution by the standard deviation. A t-test pairs of samples were used to determine if developed muscle strength and flexion of the spine in a vertical position are statistically significantly $(p<0.05)$ different. All measured results were processed using IBM SPSS Statistics20.

To estimate standard deviation, measurements for 100 and 80 persons of Table 1 were used. These measurements were performed at least twice for every person. 

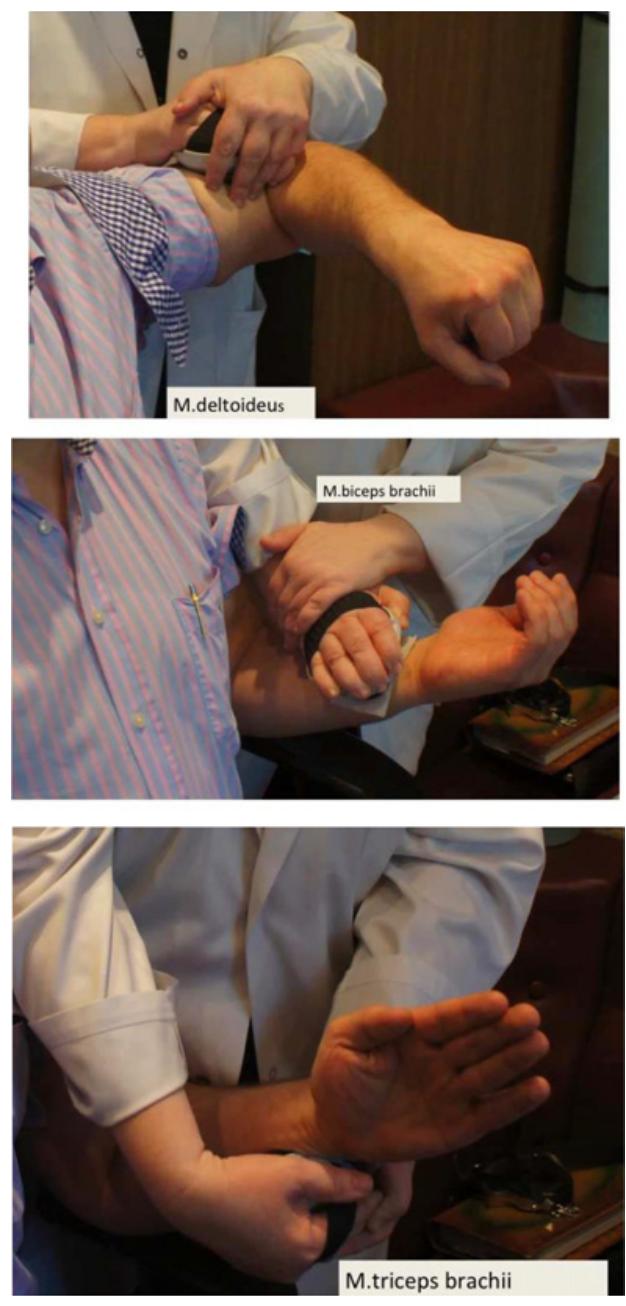

Fig. 2. Experimental setup for measurements of strength of the muscles of the hand and arm.

\section{Analysis of results}

All results of measurements are presented in Tables 2, 3 and 4. The results in these tables show statistically significant changes in two of four muscles we tested (M. deltoideus and $M$. triceps brachii) when the maximum strength values are obtained for the cervical spine in the vertical position and when the head is in full flexion.

Mean values of the extremities muscle strength. Abbreviations: $\mathrm{v}-$ the spine is vertical; $\mathrm{f}$ - flexio capitis; 1 - the left side; $\mathrm{r}$ - right side; digits - the size of the number in the database. For example: v1l - Abductor Pollicis Longus - the left side muscle, spine upright.

We find statistically significant differences between the muscle strength of the spine in vertical position and full flexio capitis (maximally head flexion) position for 2 of 4 pair of tested muscles (M. triceps brachii and M. deltoideus). In comparison - with $30^{\circ}$ head flexion statistically significant diferences were found for 3 of 4 pair of tested muscles (M. deltoideus, M. biceps brachii, $M$. triceps brachii). Differences of the $M$. biceps brachii results of full head flexion in compare to $30^{\circ}$ head flexion could be explained by measurements scattering. 
Table 2. Summary of measurements.

\begin{tabular}{|c|c|c|c|c|c|c|c|}
\hline & \multirow{2}{*}{ Muscles } & \multicolumn{2}{|c|}{ The average value $(\mathrm{N})$} & \multicolumn{2}{|c|}{$\begin{array}{l}\text { Standard } \\
\text { deviation }(\mathbf{N})\end{array}$} & \multicolumn{2}{|c|}{$\begin{array}{l}\text { Statistical } \\
\text { significance } p\end{array}$} \\
\hline & & $\begin{array}{l}\text { Flexion } \\
30^{\circ}\end{array}$ & $\begin{array}{l}\text { Full } \\
\text { flexion }\end{array}$ & $\begin{array}{l}\text { Flexion } \\
30^{\circ}\end{array}$ & $\begin{array}{l}\text { Full } \\
\text { flexion }\end{array}$ & $\begin{array}{l}\text { Flexion } \\
30^{\circ}\end{array}$ & $\begin{array}{l}\text { Full } \\
\text { flexion }\end{array}$ \\
\hline Pair 1 & $\begin{array}{l}\text { v1l Abductor } \\
\text { Pollicis Longus } \\
\text { f11 Abductor } \\
\text { Pollicis Longus }\end{array}$ & $\begin{array}{l}51.1 \\
53.3\end{array}$ & $\begin{array}{l}48.8 \\
57.1\end{array}$ & $\begin{array}{l}26.1 \\
26.5\end{array}$ & $\begin{array}{l}28.3 \\
41.5\end{array}$ & 0.092 & 0.059 \\
\hline Pair 2 & $\begin{array}{l}\text { v31 Biceps Brachii } \\
\text { f31 Biceps Brachii }\end{array}$ & $\begin{array}{l}123.1 \\
113.2\end{array}$ & $\begin{array}{l}124.8 \\
123.6\end{array}$ & $\begin{array}{l}56.8 \\
49.3\end{array}$ & $\begin{array}{l}54.2 \\
59.7\end{array}$ & 0.004 & 0.687 \\
\hline Pair 3 & $\begin{array}{l}\text { a41 Triceps Brachii } \\
\text { b4l Triceps Brachii }\end{array}$ & $\begin{array}{l}121.4 \\
108.6\end{array}$ & $\begin{array}{l}131.3 \\
118.0\end{array}$ & $\begin{array}{l}57.0 \\
52.0\end{array}$ & $\begin{array}{l}56.8 \\
49.8\end{array}$ & $<0.001$ & $<0.001$ \\
\hline Pair 4 & $\begin{array}{l}\text { v5l Midle Deltoid } \\
\text { f51 Midle Deltoid }\end{array}$ & $\begin{array}{r}107.3 \\
96.9\end{array}$ & $\begin{array}{l}97.7 \\
91.6\end{array}$ & $\begin{array}{l}45.4 \\
43.6\end{array}$ & $\begin{array}{l}37.8 \\
39.9\end{array}$ & $<0.001$ & 0.004 \\
\hline Pair 5 & $\begin{array}{l}\text { v1r Abductor } \\
\text { Pollicis Longus } \\
\text { f1r Abductor } \\
\text { Pollicis Longus }\end{array}$ & $\begin{array}{l}50.3 \\
51.0\end{array}$ & $\begin{array}{l}43.2 \\
46.4\end{array}$ & $\begin{array}{l}29.5 \\
27.1\end{array}$ & $\begin{array}{l}24.3 \\
24.3\end{array}$ & 0.678 & 0.060 \\
\hline Pair 6 & $\begin{array}{l}\text { v3r Biceps Brachii } \\
\text { f3rl Biceps Brachii }\end{array}$ & $\begin{array}{l}144.7 \\
133.1\end{array}$ & $\begin{array}{l}138.8 \\
139.4\end{array}$ & $\begin{array}{l}68.5 \\
62.4\end{array}$ & $\begin{array}{l}59.4 \\
63.1\end{array}$ & 0.006 & 0.845 \\
\hline Pair 7 & $\begin{array}{l}\text { v4r Triceps Brachii } \\
\text { f4r Triceps Brachii }\end{array}$ & $\begin{array}{l}132.3 \\
120.2 \\
\end{array}$ & $\begin{array}{l}132.4 \\
121.9 \\
\end{array}$ & $\begin{array}{l}57.6 \\
50.3 \\
\end{array}$ & $\begin{array}{l}52.9 \\
50.4 \\
\end{array}$ & $<0.001$ & 0.002 \\
\hline Pair 8 & $\begin{array}{l}\text { v5r Midle Deltoid } \\
\text { f5r Midle Deltoid }\end{array}$ & $\begin{array}{r}107.6 \\
99.1\end{array}$ & $\begin{array}{r}103.3 \\
91.8\end{array}$ & $\begin{array}{l}44.1 \\
41.8\end{array}$ & $\begin{array}{l}41.2 \\
38.4\end{array}$ & $<0.001$ & $<0.001$ \\
\hline
\end{tabular}

Table 3. Changes in left side limb muscle strength measured in Newtons (N) in the spine (in vertical position with flexed cervical and lumbar spine) compared to the left and right sides.

\begin{tabular}{|l|c|c|c|c|}
\hline & $\begin{array}{c}\text { Abductor } \\
\text { pollicis longus }\end{array}$ & $\begin{array}{c}\text { Biceps } \\
\text { brachii }\end{array}$ & $\begin{array}{c}\text { Triceps } \\
\text { brachii }\end{array}$ & $\begin{array}{c}\text { Deltoid, } \\
\text { middle part }\end{array}$ \\
\hline Flexion 30 & & & & \\
\hline Vertical & $51.1(26.1)$ & $123.1(56.8)$ & $121.4(57.0)$ & $107.3(45.4)$ \\
\hline Flexion & $53.3(26.5)$ & $113.2(49.3)$ & $108.6(52.0)$ & $96.9(43.6)$ \\
\hline Statistical significance $\mathrm{p}^{1}$ & 0.092 & 0.004 & $<0.001$ & $<0.001$ \\
\hline Strength change \% & +4.4 & -8.1 & -10.5 & -9.6 \\
\hline Full flexion & & & & \\
\hline Vertical & $48.8(28.3)$ & $124.8(54.2)$ & $131.3(56.8)$ & $97.7(37.8)$ \\
\hline Flexion & $57.1(41.5)$ & $123.6(49.3)$ & $118.0(49.8)$ & $91.6(39.9)$ \\
\hline Statistical significance $\mathrm{p}^{1}$ & 0.059 & 0.687 & $<0.001$ & 0.004 \\
\hline Strength change \% & +16.5 & -1.0 & -10.7 & -6.2 \\
\hline Statistical significance $\mathrm{p}^{2}$ & 0.130 & 0.253 & 0.761 & 0.263 \\
\hline
\end{tabular}

Values in brackets show standard deviation $\rho$ in Newtons $(\mathrm{N})$.

$\mathrm{p}^{1}$ - statistical significance of difference between muscle strength in vertical and flexion positions

$\mathrm{p}^{2}$ - statistical significance of difference between changes of force in booth flexions

Strength change $\%=(\mathrm{N} 1-\mathrm{N} 2) / \mathrm{N} 1 * 100 \%$; N1 - muscle strength when Vertical; N2- muscle strength when Flexed; "+" if strength increases when flexed "-" if strength decreases when flexed. 
Table 4. Changes in rightside limb muscle strength measured in Newtons $(\mathrm{N})$ in the spine (in vertical position with flexed cervical and lumbar spine) compared to the left and right sides.

\begin{tabular}{|c|c|c|c|c|}
\hline & $\begin{array}{c}\text { Abductor } \\
\text { pollicis longus }\end{array}$ & $\begin{array}{l}\text { Biceps } \\
\text { brachii }\end{array}$ & $\begin{array}{l}\text { Triceps } \\
\text { brachii }\end{array}$ & $\begin{array}{l}\text { Deltoid, } \\
\text { middle part }\end{array}$ \\
\hline \multicolumn{5}{|l|}{ Flexion $30^{\circ}$} \\
\hline Vertical & $50.3(29.5)$ & $144.7(68.5)$ & $132.3(57.6)$ & $107.6(44.1)$ \\
\hline Flexion & $51.0(27.1)$ & $133.1(62.4)$ & $120.2(50.3)$ & $99.1(41.8)$ \\
\hline Statistical significance $\mathrm{p}^{1}$ & 0.678 & 0.006 & $<0.001$ & $<0.001$ \\
\hline Strength change $\%$ & +1.3 & -8.0 & -9.1 & -7.9 \\
\hline \multicolumn{5}{|l|}{ Full flexion } \\
\hline Vertical & $43.2(24.3)$ & $138.8(59.4)$ & $132.4(52.9)$ & $103.3(41.2)$ \\
\hline Flexion & $46.4(27.1)$ & $139.4(63.1)$ & $121.9(50.4)$ & $91.8(38.4)$ \\
\hline Statistical significance $\mathrm{p}^{1}$ & 0.060 & 0.845 & 0.002 & $<0.001$ \\
\hline Strength change $\%$ & +7.4 & +0.4 & -7.9 & -11.1 \\
\hline Statistical significance $\mathrm{p}^{2}$ & 0.260 & 0.349 & 0.897 & 0.153 \\
\hline
\end{tabular}

Values in brackets show standard deviation $\rho$ in Newtons $(\mathrm{N})$.

$\mathrm{p}^{1}$ - statistical significance of difference between muscle strength in vertical and flexion positions

$\mathrm{p}^{2}$ - statistical significance of difference between changes of force in booth flexions

Strength change $\%=(\mathrm{N} 1-\mathrm{N} 2) / \mathrm{N} 1 * 100 \%$; N1 - muscle strength when Vertical; N2- muscle strength when Flexed; "+"

if strength increases when flexed "-" if strength decreases when flexed.

Comparison of the muscles strength changes $(\%)$ of both cases $\left(30^{\circ}\right.$ and full flexion) show no statistically significant differences, $p>0.05$. The observed decreasing in muscle strength phenomenon manifest itself like with the $30^{\circ}$ head flexion and the maximal flexion of the head.

Overall, we are confident that, combining the main results of this study, head flexion at $30^{\circ}$ and greater than $30^{\circ}$ - full flexion can change the relative strength muscles of upper extremities. Since we have not found any statistical significant changes in muscle strength in the $M$. abductor pollicis longus being innervated from $\mathrm{C} 8$ segment, we can conclude that the flexion of the head is created a mechanical stretch mostly of the segments C5-C7 and neutral mechanical stretch is in the $\mathrm{C} 8$ segment.

\section{Discussion}

Registering the muscle groups where the changes in strength is observed during head bending forward we can accurately say that the fifth, sixth and seventh segment of spinal cord is affected as the responsible sites for those muscles.

It is a very important result of this study, because it clearly demonstrates that while changing curvature of cervical spine from lordosis to kyphosis position changes occur also within the spinal cord, not only in the spine, spinal nerves or neck/shoulder muscles.

We supposed the possible reason that could lead to a rapid and reversible change in the innervation of the muscles on the right and left side is a mechanical stretch of the spinal cord and the changes in the blood supply to the spinal cord. Once again, we emphasize that it is a normal function of the locomotion apparatus in healthy subjects, not associated with pain or any subjective or functional impairment. The mechanical nervous stretch with an elongation within $5-12 \%$ range may cause transient disturbances in innervation. Since the spinal cord is made of nervous tissue, it can be assumed that this mechanism could be one of the reasons 
for the relative change in the muscle strength phenomenon. During a longitudinal stretch of peripheral nerves, the increase in intraneural pressure occurs in proportion to the width of the nerves [12].

The blood supply to the spinal cord system is complex, with high adaptability under various functional conditions, and it is composed out to three large longitudinal arterial trunks. Together, these trunks constitute a single circulatory circle. On the other hand, the spinal cord gray and white matter has blood supply which is carried out by the segmental artery and terminal branches. These arteries are perpendicular to the longitudinal axis of the spinal cord. Using our experimental study we can conclude that the changes in blood supply will be directly affected by the spinal cord deformation caused by the mechanical stretch [7]. Because of this, it is most likely that the segmentally vessels will be compressed, worsening the blood supply of the segment. At the same time, the neural functional capabilities are directly dependent on the adequate blood supply [9-11].

The cervical spine position changes kyphosis to lordosis physiological extent, by flexio capitis leads to a significant change in muscle strength between the right and left side, that is causing the asymmetric changes in arm muscle (M. deltoideus, M. biceps brachii, M. triceps brachii) strength.

The flexed body's position of the regular computer, notebooks, mobile phones users affects the blood circulation in cervical region of spinal cord, and as result - also strength in some of the upper limb muscles. Posture and the functional status of the spinal cord are important factors in various spinal pathology-related diseases. These factors must be taken into consideration because the flexion of the neck, and the position of the body may be overextended some periods of time, on a daily basis.

\section{Conclusions}

The neck functional changes from lordosis to kyphosis position potentially affect areas of the spinal cord in the C5, C6 and C7 segments, which are responsible for the corresponding muscle innervation. (C5-for M. deltoideus, C6-for M. biceps brachii, C7-for M. triceps brachii).

We can conclude that there is strong relationship in the change in some of the observed muscles (M. deltoideus, $M$. triceps brachii) between vertical position and full flexion of head. The results of our present study support the hypothesis that the changes in the strength of these muscles are related to the mechanical distension of the spinal cord, which leads to changes in blood supply to the spinal cord.

\section{References}

[1] M. Hagberg, E.W. Tornqvist, A. Toomingas, J. Occup. Rehabil. 12(3), 151-62 (2002)

[2] T.R. Hales, S.L. Sauter, M.R. Peterson, L.J. Fine, V. Putz-Anderson, L.R. Schleifer, T.T. Ochs, B.P. Bernard, Ergonomics 37(10), 1603-21 (1994)

[3] K.A. Holte, R.H. Westgaard, Amer. J. Ind. Med. 41, 393-405 (2002)

[4] T. Theorell, K. Harms-Ringdahl, G. Ahlberg-Hulten, B. Westin, Scand. J. Rehabil. Med. 23(3), 165-73 (1991)

[5] J. Wahlstr, M. Hagberg, A. Toomingas, E. Wigaeus Tornqvist, Occup. Environ. Med. 61(6), 523-8 (2004)

[6] O. Vasseljen, K.A. Holte, R.H. Westgaard, Ergonomics 44(4), 355-72 (2001)

[7] M. Shacklock, Clinical Neurodynamics, A new system of musculoskeletal treatment (Elsevier, 2005) 
[8] J. Vētra, V. Sklarevich, L. Beilina, G. Anoufriev, I. Kalniņš, S. Umbraško, V. Kotovs, Statistical analysis of extreme changes in the muscular strength in the extremities, Chalmers Publication Library, Preprint, 19/12/2014. (http: //publications . lib. chalmers.se/publication/208751-statistical-analysis-of-extremechanges-in-the-muscular-strength-in-the-extremities)

[9] Y. Fujita, H.T. Yamamoto, Nippon Seikeigeka Gakkai Zasshi 62(4), 359-368 (1988)

[10] G. Lundborg, B. Rydevik, J. Bone Joint Surg. 55B, 390-401 (1973)

[11] K. Ogata, M. Naito, J. Hand Surg. 11B(1), 10-14 (1986)

[12] J.-P. Barral, A. Croibier, Manual Therapy for the Peripheral Nerves (Churchill Livingstone, Esevier, 2007), p. 48 